\title{
Design of embankment for safe back filling in opencast mines: A case study
}

\author{
Santosh Kumar Behera, Prashant, CN Ghosh and PK Mandal \\ CSIR-CIMFR \\ Dhanbad, India \\ skb@cimfr.res.in
}

\begin{abstract}
Disposal of coal ash generated by thermal power plants is a challenge now days under rigid environmental norms. The conventional method of disposing in ash ponds leads to requirement of huge amount of valuable land and it have adverse effect on air, ground water and soil. Hence, the need of the hour is to utilize this ash in an environment friendly manner. In this paper a technical option for safe back filling practices by constructing embankment in the de-coaled area is discussed. This paper throws a light on the scheme for utilizing coal ash in combination with overburden $(\mathrm{O} / \mathrm{B})$ material as a filling material in abandoned portion of the mine. The filling work is carried out by design of embankment to contain it against the high wall. Out of several methods of embankment construction, downstream method of embankment method is used. To design embankment safely numerical simulation was carried out by using PLAXIS-3D which is based on Finite Element Method. The construction scheme involves raising of embankment with slope angle of 270in eight stages of ten meters height each and simultaneously filling it with high concentration ash in layers. The material used for embankment construction was coal ash and $O B$. In the final stage, the top soil of $5 \mathrm{~m}$ thick is proposed to be spread for re-vegetation.
\end{abstract}

Keywords-Back fill; Coal ash; embankment; downstream; PLAXIS-3D

\section{INTRODUCTION}

The utility electricity sector in India had an installed capacity of $298 \mathrm{GW}$ as of 31 March 2016 [1] consuming about 550 MT of coal and generating $184 \mathrm{Mt}$ of ash per annum [2]. Over 100,000 MW additional generation need to be added in the next ten years to bridge the gap between demand and supply of power. With this anticipated growth in the generation of thermal power, the demand for coal and hence the generation of ash will increase simultaneously.

Despite of rigorous efforts by Govt. of India through mission mode activities and notifications of MOEF (14th Sept. 1999, 27th Aug. 2003 and 3rd Nov.2009) floated and amended from time to time, the desired target of $100 \%$ ash utilization by the year 2014 could not be achieved. The current utilization of ash in India is about $58 \%$ which is lesser than china (67\%), Japan (96\%) and Europe (91\%) [3]. Coal ash is mainly utilized in agriculture, cement, concrete, reclamation, mine filling etc. and the contribution of mine filling towards ash utilization is mere $13 \%$ [2]. The option of large scale environment friendly utilization of ash in opencast mine as high concentration slurry fill can lead to a quantum jump to achieve the set target.

In this paper an attempt has been made to device a scheme for construction of embankment to facilitate ash disposal at high concentration in de-coaled portion of Gare IV/I mine at Tamnar, Chhattisgarh. This mine is located between longitudes $83^{\circ} 31^{\prime} 50^{\prime \prime}$ to $83^{\circ} 33^{\prime} 49^{\prime \prime}$ and latitude $22^{\circ} 05^{\prime} 37^{\prime \prime}$ to $22^{\circ} 07^{\prime} 44$. The coal seam at sub-slock IV/1 belongs to the Barakar formation and has a strike of the beds is North-west 300 to 550 toSouth-East 300 to 550 dipping towards south-west at an angle of 30 to 40 . There are six coal seams of varying thickness from 3 to $8 \mathrm{~m}$ and, seam no VIII and IX are exposed in this block. Lithology of the area is shown in Table 1. This mine is divided into two pits, in Pit I complete extraction of coal had been done with a depth of $80-85 \mathrm{~m}$. Out of the two location options for proposed erection of embankment at Pit-I as shown in Fig.1, the location across section B - B' was selected as it offered larger area and Ideals with high wall at the dip side and with one side wall along the strike.

TABLE. 1. GenERAL Lithology OF THE AREA.

\begin{tabular}{|c|c|c|}
\hline $\begin{array}{c}\text { Seam/ } \\
\text { Parting }\end{array}$ & $\begin{array}{c}\text { Variation in } \\
\text { thickness (m.) }\end{array}$ & Grade/ Formations \\
\hline $\mathrm{X}$ & $0.53-2.73$ & $\mathrm{G}$ \\
\hline Parting & $3.72-9.17$ & $\begin{array}{c}\text { Fine- coarse Sandstone (SS) and } \\
\text { shale }\end{array}$ \\
\hline XA & $0.91-3.17$ & $\mathrm{G}$ \\
\hline Parting & $34.02-48.60$ & Fine - medium SS and shale \\
\hline IX & $2.51-9.00$ & $\mathrm{~F}$ \\
\hline Parting & $1.09-8.12$ & Fine - medium SS and shale \\
\hline VIII & $0.58-5.64$ & $\mathrm{G}$ \\
\hline Parting & $2.00-12.11$ & Fine - medium SS and shale \\
\hline VII Top & $0.34-4.99$ & $\mathrm{G}$ \\
\hline Parting & $1.14-6.16$ & Fine - medium SS and shale \\
\hline VII Bottom & $0.16-2.74$ & $\mathrm{G}$ \\
\hline
\end{tabular}

Several samples of pond ash (PA) and overburden (OB) material were collected from the mine site and were analysed to determine various physico-mechanical properties. These studies included determination of specific gravity, bulk density, porosity, grain size distribution, 
permeability, compaction characteristics, shear strength, Atterburg's limits test and Standard Procter Test. Different configuration of embankment construction

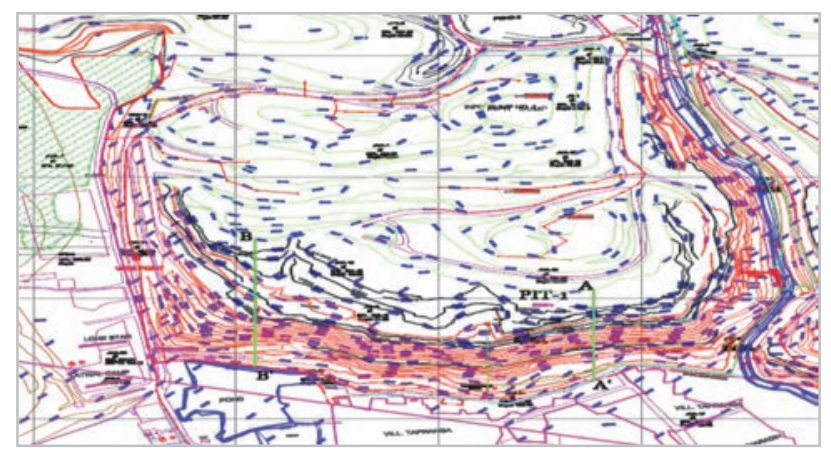

Fig.1. Part plan of Gare IV/I Mine showing section B-B' across which the embankment is proposed

\section{Methodology}

viz. upstream method, downstream method and centreline method were studied, downstream method (Fig. 2) for embankment construction was selected for stability analysis as it is most stable under dynamic loading. Downstream embankment starts with a pervious (free draining) starter dyke foundation and the high concentration ash slurry would be deposited behind the dyke and subsequent dyke raising is carried out in stages on the downstream side, so that the embankment crest is shifted towards downstream. The embankment construction and subsequent filling is shown in Fig. $3 \& 4$. This method also offers advantages like enhanced stability, control of placement and compaction as required over the entire filling operation.

Stability analysis of embankment was carried out by using PLAXIS-3D which is based on Finite Element Method. The input parameters to be used in numerical simulation were determined during laboratory studies as mentioned above.

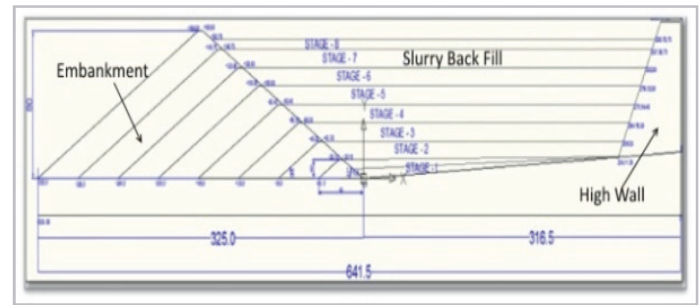

Fig. 2. Downstream embankment construction method

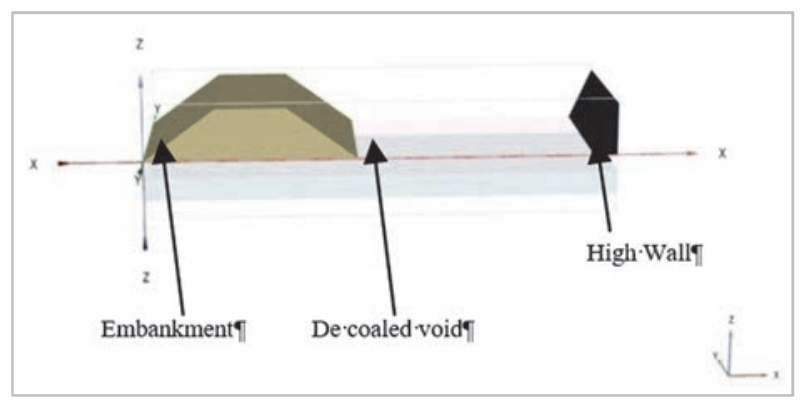

Fig. 3. Constructed embankment without back fill

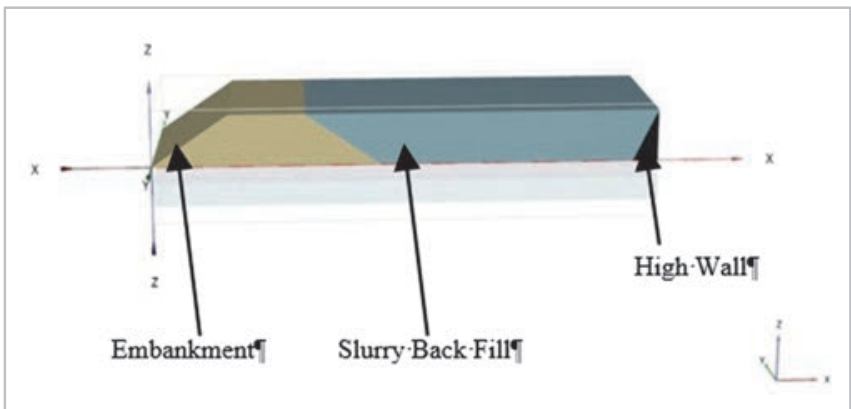

Fig. 4. Constructed embankment with back fill in remaining void areas

\section{RESULTS AND DISCUSSION}

The specific gravity and bulk density of pond ash (PA) was found to be 2.24 and $1.08 \mathrm{~g} / \mathrm{cm} 3, \mathrm{OB}$ was found to be 2.50 and $1.6 \mathrm{~g} / \mathrm{cm} 3$ respectively. The result indicated that the OB is much denser and heavier than PA. From the results of grain size distribution found that $\mathrm{PA}$ and $\mathrm{OB}$ have an average grain size (D50) of $110 \mu \mathrm{m}$ and $450 \mu \mathrm{m}$ respectively.

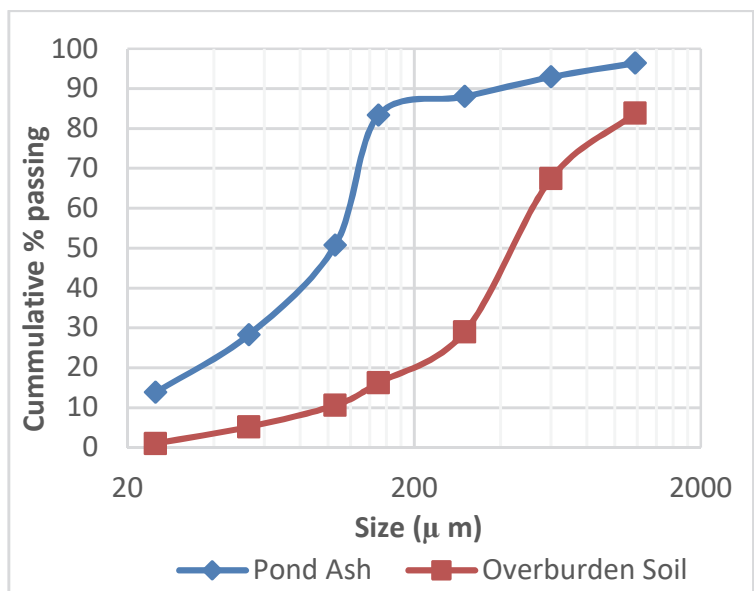

Fig. 5. Grain size distribution of PA \& OB

The porosity of PA was found to be $51.79 \%$ whereas that of OB was found out to be $36 \%$, this may be attributed to the fact that PA is more uniformly graded as shown in the Fig. 5. The permeability of PA was found to be $10.5 \mathrm{~cm} / \mathrm{hr}$ and OB was found to be $13.76 \mathrm{~cm} / \mathrm{hr}$ as measured by constant head permiameter. Low infiltration rate of water in the ash can be due to hydration of calcium in the ash when in contact with water, which leads to change in its porosity. The direct shear test on $\mathrm{OB}$ sample indicated an average cohesion value of $0.087 \mathrm{MPa}$ and an angle of internal friction of 280, where as that of PA material was found out to be $0.096 \mathrm{MPa}$ and 19.70 respectively. Consistency limits or Atterberg's limit test designed by Casagrande [4] on PA and OB material were carried out in the laboratory to determine its plastic properties and was found that both materials were nonplastic in nature. Standard Procter Test [5] was carried out in the laboratory to determine the compaction characteristics of both PA and OB material, the result of which are shown in Fig. $6 \& 7$ respectively. It was observed that the maximum dry density (MDD) of $1.242 \mathrm{~g} / \mathrm{cm} 3$ by PA is reached at optimum moisture content (OMC) of $23.25 \%$ and for $\mathrm{OB}$ material the MDD of $1.83 \mathrm{~g} / \mathrm{cm} 3$ is reached at $14.73 \% \mathrm{OMC}$ 


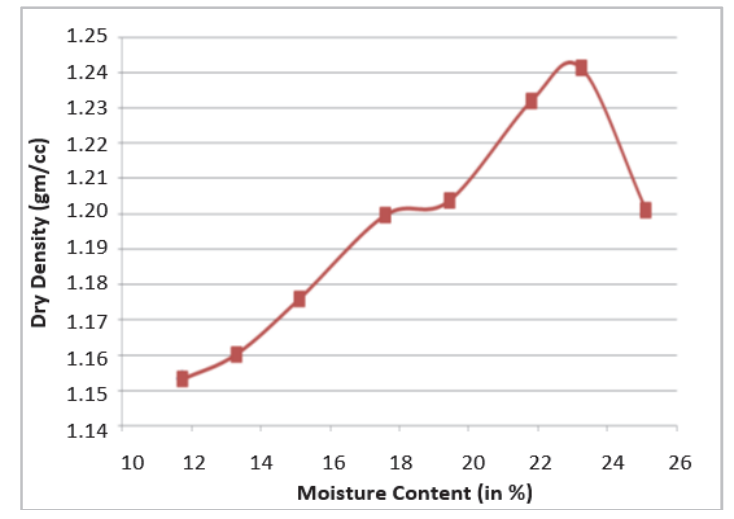

Fig. 6. Dry density Vs Water content of PA

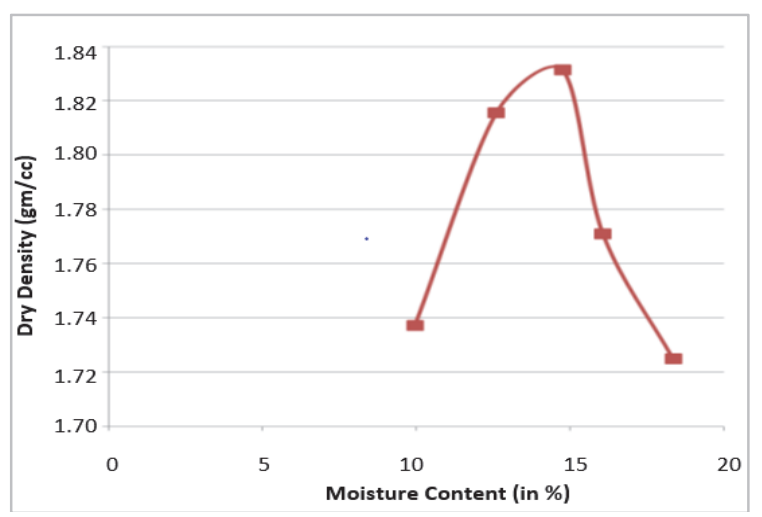

Fig. 7. Dry density Vs Water content of $\mathrm{OB}$

\section{LIMIT EQUILIBRIUM METHOD}

The simplified Bishop's method is an extension of the method of slices and is generally used for calculating safety factors of slopes. As shown in Fig. 6, weight of ith slice (Wi) acts vertically downward. The resistive force (Ti) and normal force (Ni) act at the base of the slice. By simplifying the assumptions that force on one sides of each slice are horizontal and no shear force exists at the vertical sides of the slice, the problem becomes statically and suitable for hand calculations. The method has been shown to produce factor of safety value within a few percentage of the "correct" values. The equation 1 represents the safety factor of slopes based on Bishop's method [6].

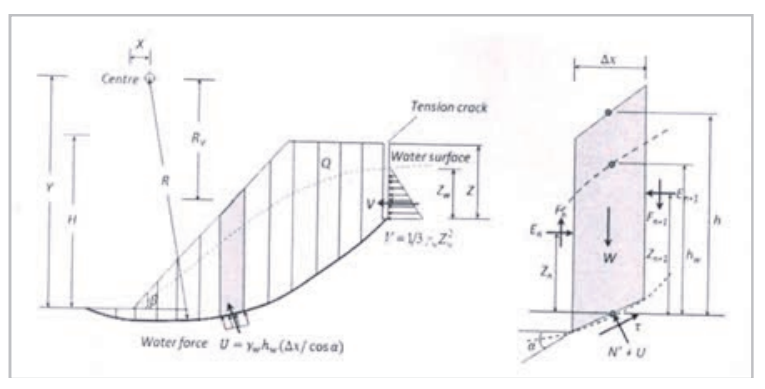

Fig. 8. Bishops simplified method of slices

$$
\mathrm{FOS}=\frac{\sum \frac{\left(c+\gamma_{r} h_{i}\left(1-r_{u}\right) \tan \varphi\right)\left(\Delta x \sec \alpha_{i}\right)}{1+\frac{1}{F O S} \tan \alpha_{i} \tan \varphi}}{\sum W_{i} \sin \alpha_{i}+V\left(\frac{R_{V}}{R}\right)}
$$

where: FOS is the safety factor, $\mathrm{c}$ is the cohesion, $\varphi$ is the angle of internal friction, bi is the width of each slice, assuming that all slices have the same width, Wi is the weight of each slice, $r_{u i}$ is the pore water pressure of each slice as defined in Equation 2.

$$
r_{u}=\frac{u}{\gamma_{r} h}=\frac{\gamma_{w} h_{w}}{\gamma_{r} h}
$$

Where, $\gamma_{\mathrm{w}}$ and $\gamma_{\mathrm{r}}$ are bulk density of water and geomaterial respectively. The parameters, $h_{w}$ and $h_{r}$ are height of piezometric surface and that of slice respectively as shown in Fig. 8. The pore pressure ratio $r_{u}$ is assumed to be constant throughout the cross section, which is called homogenous pore pressure distribution. SF is obtained by iterative method. An initial value of SF is assumed and the Newton-Raphson or other iterative techniques are applied to estimate the final SF until difference between SFs for two consecutive iterations is minimal.

\section{NumERICAL SimULATION FOR STABILITY ANALYSIS OF EMBANKMENT}

The phenomenon of Back Filling i.e. the consolidation of PA and OB material, stress build-up, factor of safety (FOS) analysis is studied using numerical modelling. For numerical modelling PLAXIS-3D which is based on finite element method is used.

The results of laboratory studies were utilised in the numerical modeling software (PLAXIS-3D) and the stability of downstream embankment was carried out both in drained and undrained conditions. The space available for constructing the embankment along section B- B' was calculated and a realistic geometry of the same was fed into the model. The slope angle of the embankment was kept at 270 and it was raised in stages of $10 \mathrm{~m}$ each up to a height of $80 \mathrm{~m}$ in 8 stages. Immediate floor of sandstone up to a depth of $20 \mathrm{~m}$ and water table at $2.5 \mathrm{~m}$ below the mine floor was also incorporated in the model. The slope angle of high wall was kept at 600 and vertical drains were places at an interval of $20 \mathrm{~m}$ from each other and the horizontal drains at the centre of each stage to facilitate pore water dissipation.

The volume of void, time to fill each stage was calculated at an assumed filling rate, concentration and working hours. In the pre-processing stage of PLAXIS-3D, boundary conditions, time required to fill each stage, time available for consolidation of fill and embankment was incorporated in the model. During calculation stage, analysis type is chosen such as plastic, consolidation and phi-c reduction. The loads of different stage of filling and embankment raising are activated step wise as per construction schedule. In PLAXIS3D Phi-c reduction method is used to compute FOS for embankment stability. The total multiplier $\Sigma$ Msf is used to define the value of the embankment strength parameters at a given stage in the analysis. This parameter is increased in a step by step procedure until failure ocm3urs [7].

$$
\Sigma \mathrm{Msf}=\frac{\tan \varphi_{\text {input }}}{\tan \varphi_{\text {reduced }}}=\frac{\mathrm{C}_{\text {input }}}{\mathrm{C}_{\text {reduced }}}
$$


The Safety calculation is performed using the Load advancement number of steps procedure. The incremental multiplier Msf is used to specify the increment of the strength reduction of the first calculation step. This increment is by default set to 0.1 , which is generally found to be a good starting value. The strength parameters are sucm3essively reduced automatically until all Additional steps have been performed. The number of additional steps is set to 100. It must always be checked whether the final step has resulted in a fully developed failure mechanism. If that is the case, the factor of safety is given by,

$$
\text { FOS (factor of safety) }=\frac{\text { available strength }}{\text { strength at failure }}=\text { value of } \Sigma \mathrm{Msf}
$$

at failure.

Analysis of FOS of embankment was done both with and without drains. Due to symmetry half of the embankment geometry is simulated. The geometry (Symmetric) of the model is shown in Fig. 9.

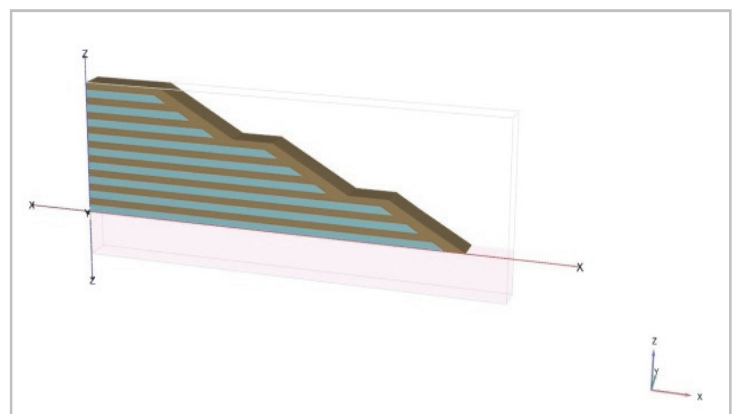

Fig. 9. Numerical Simulation Model Geometry

PLAXIS-3D generated mesh and Connectivity plot is shown in Fig. 10.

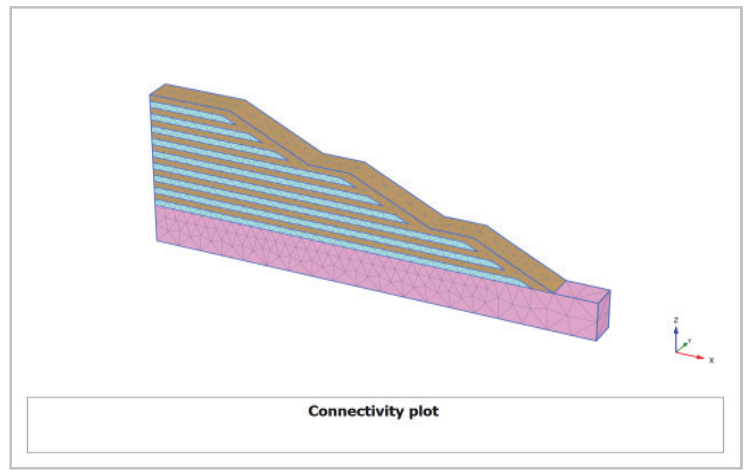

Fig. 10. Generated mesh \& Connectivity plot

In this study vertical displacement, Stress, and factor of safety are analysed by numerical simulation. Finite element mesh has been generated by using PLAXIS-3D software, having 163891 nodes and an Average element size (Ie) of 1.648 metre. The material volume in the PLAXIS program is modeled by means of 10-node tetrahedral elements [8].

Fig. 11 shows the slope movement of the embankment after construction, which shows that there is no substantial ground movement.

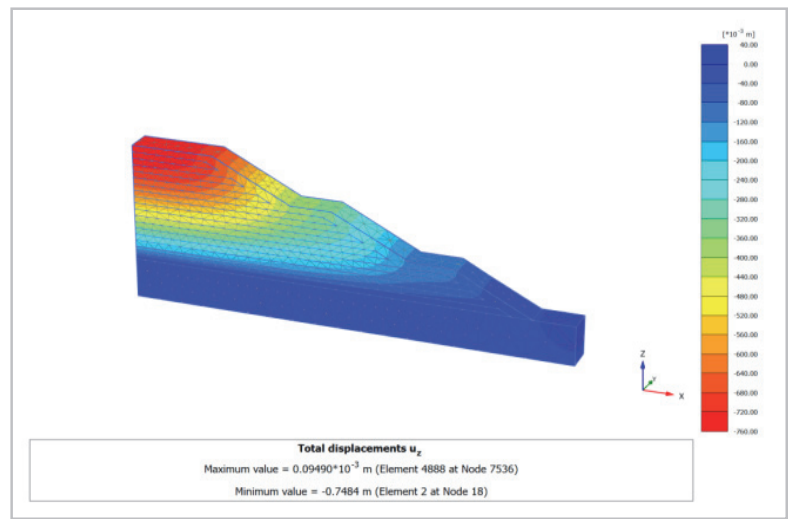

Fig. 11. Displacemnt contour shadings

Fig. 12 shows the vertical stress $\left(\sigma_{\mathrm{zz}}\right)$ shadings and vertical stress contour lines of the model geometry respectively.

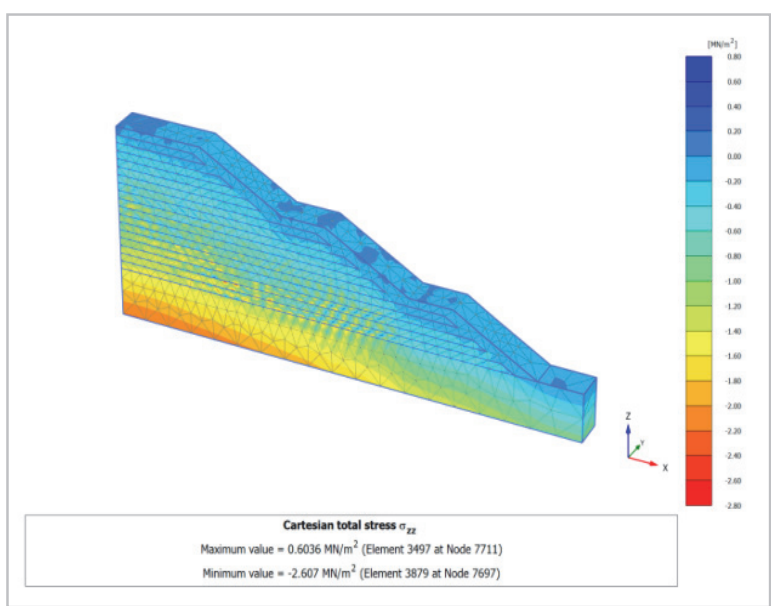

(a)

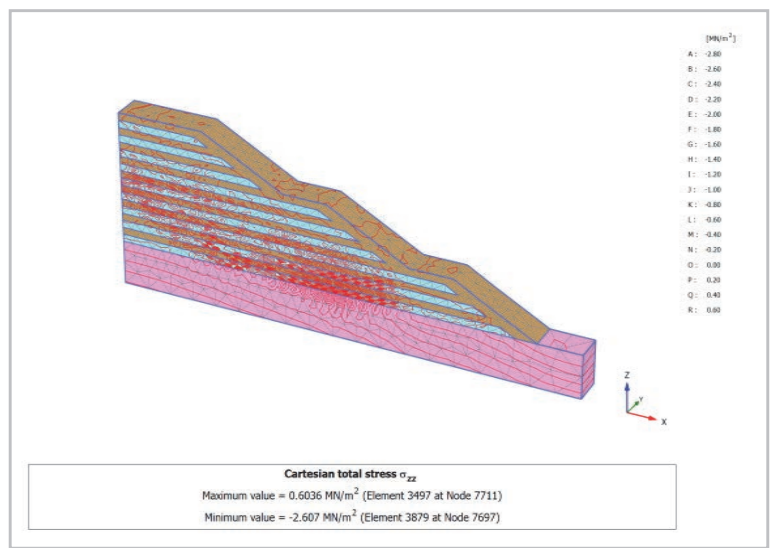

(b)

Fig. 12. vertical stress shadings and contour lines

Fig. 13 shows the Shear stress shadings and shear stress contour lines of the model geometry respectively. Fig. 14 shows the mobilised shear strength $\left(\tau_{\text {mob }}\right)$ shadings and mobilised shear strength contour lines of the model geometry respectively. 


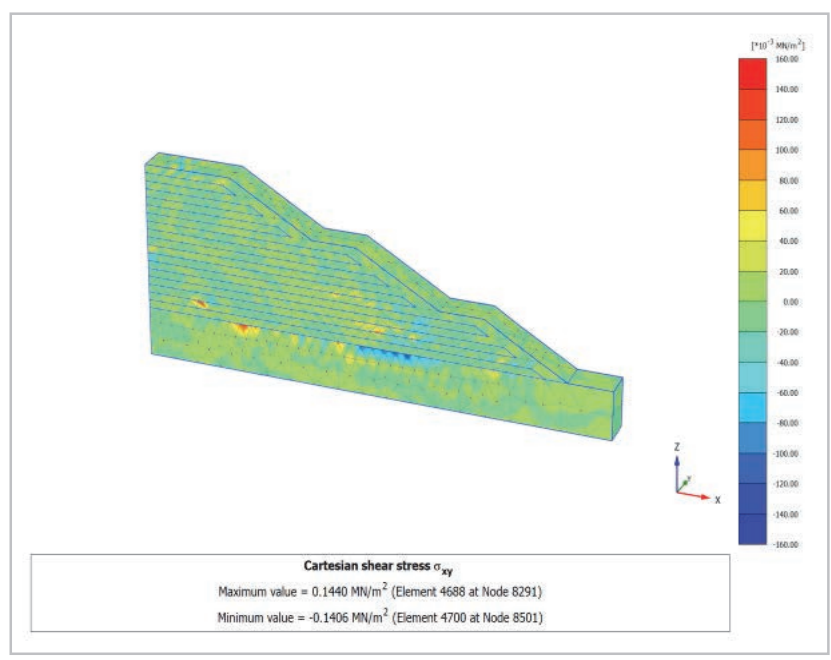

(a)

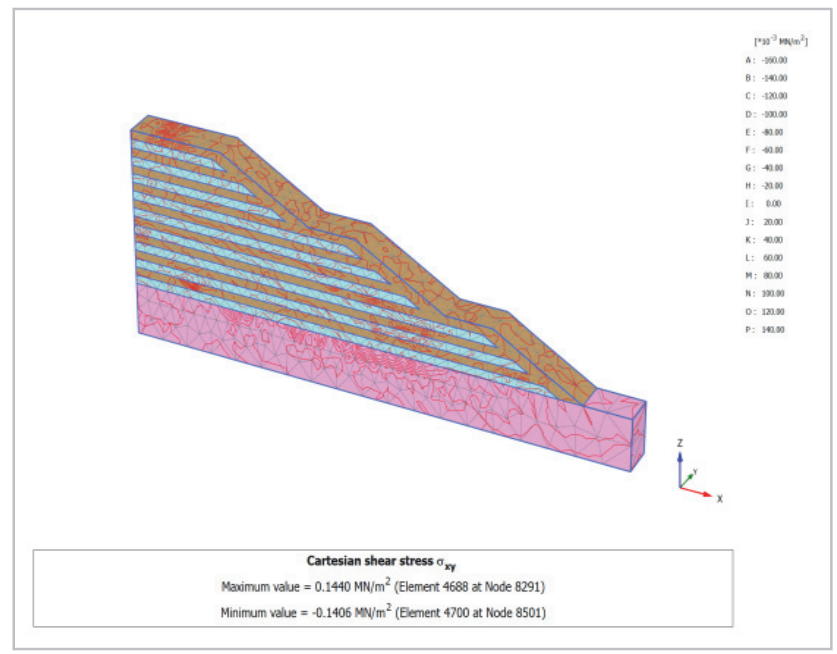

(b)

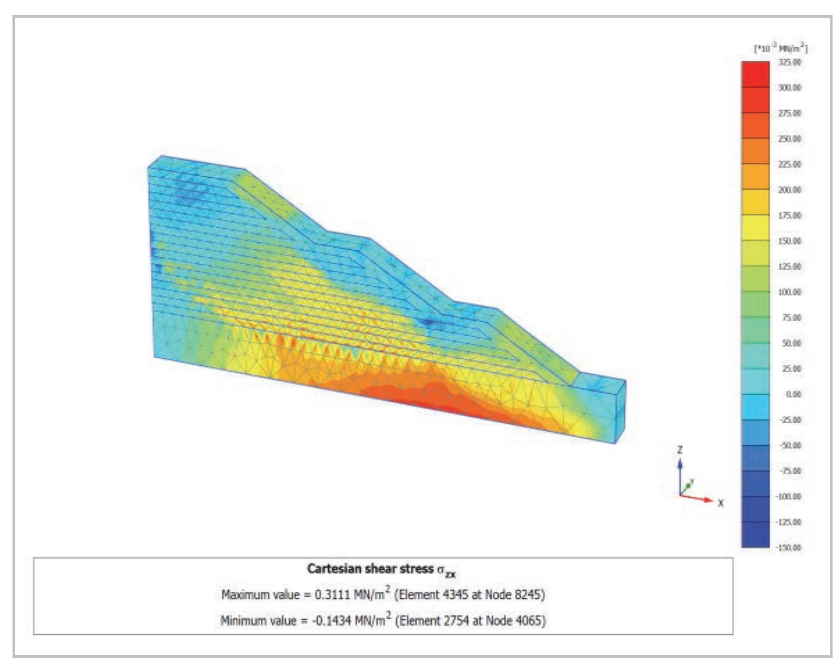

(c)

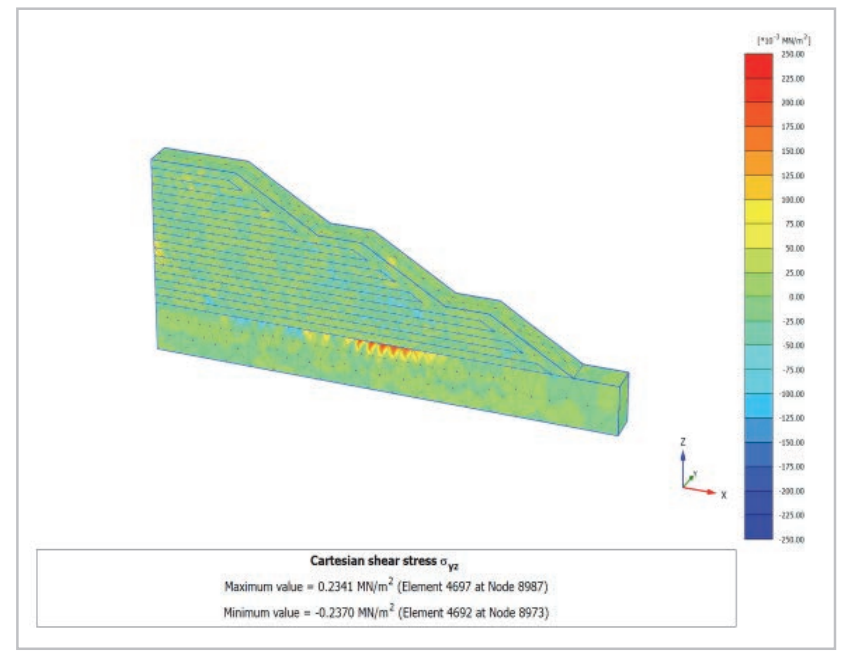

(d)

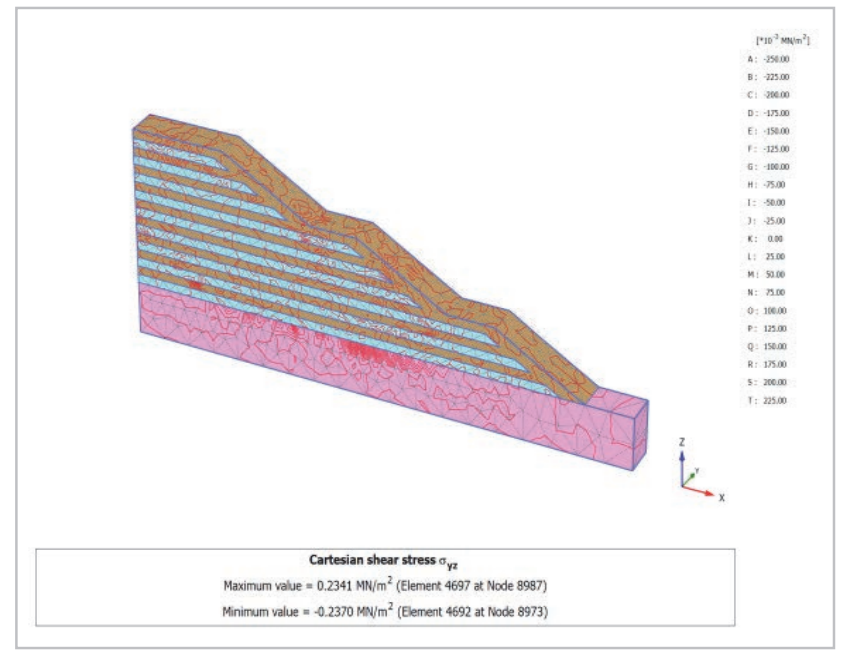

(e)

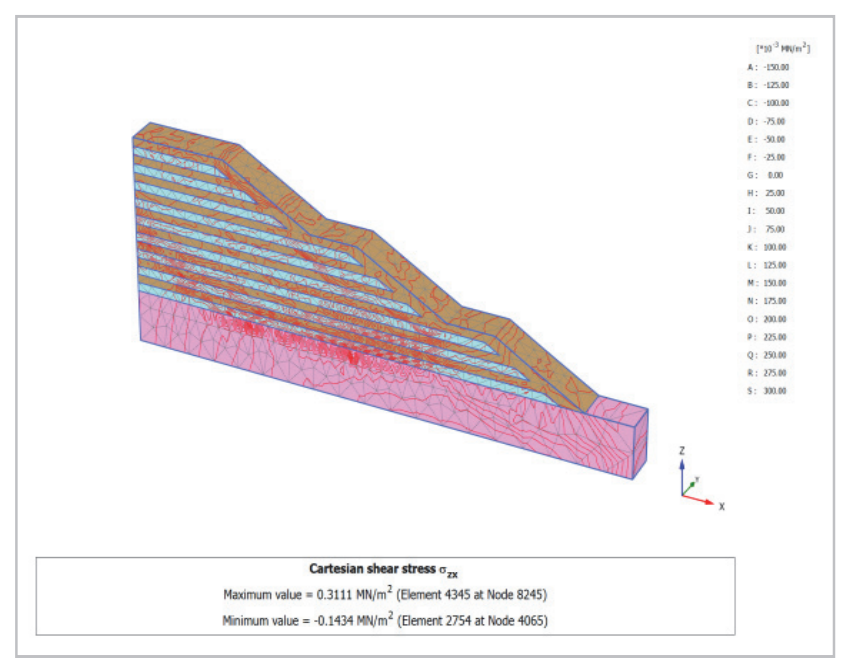

(f)

Fig. 13. (a - f) Shear stress shadings and shear stress contour lines of the model geometry 


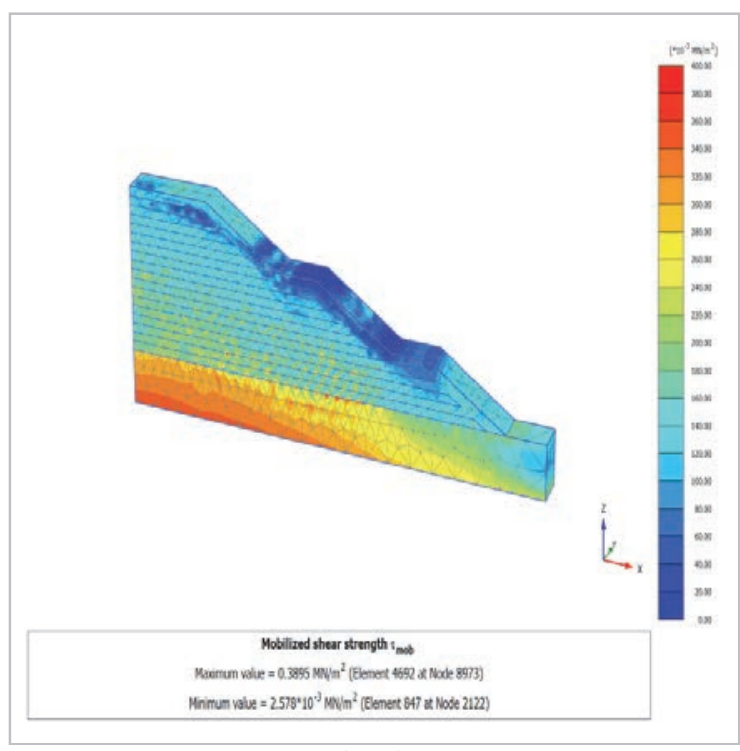

(14a)

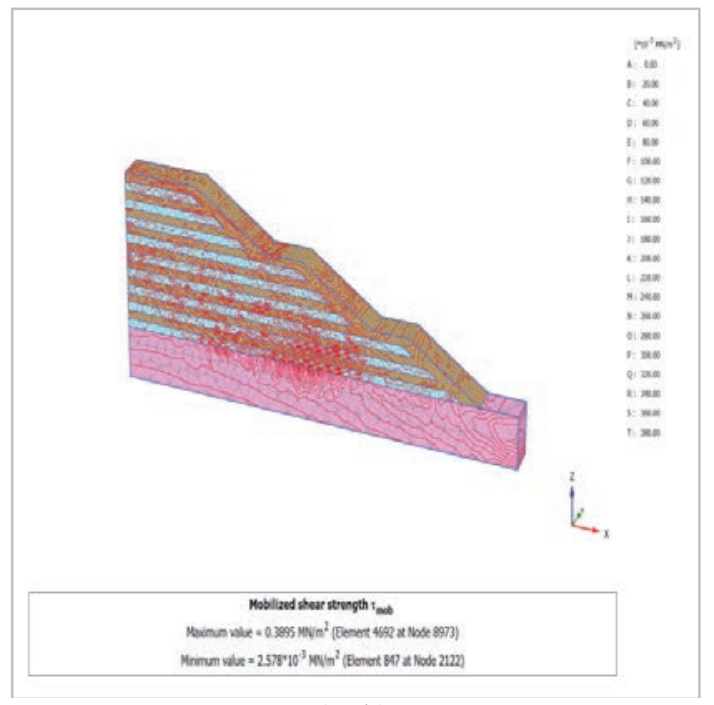

(14b)

Fig. 14. Mobilised shear strength shadings \& contour lines

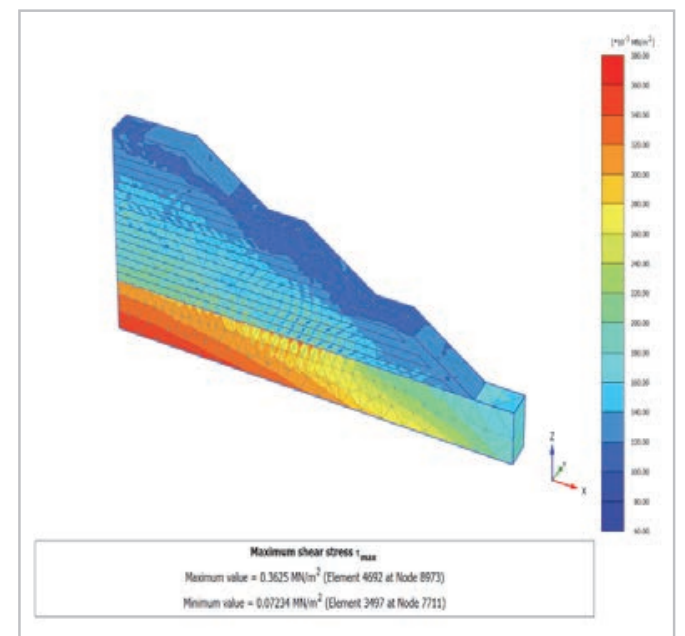

(15a)

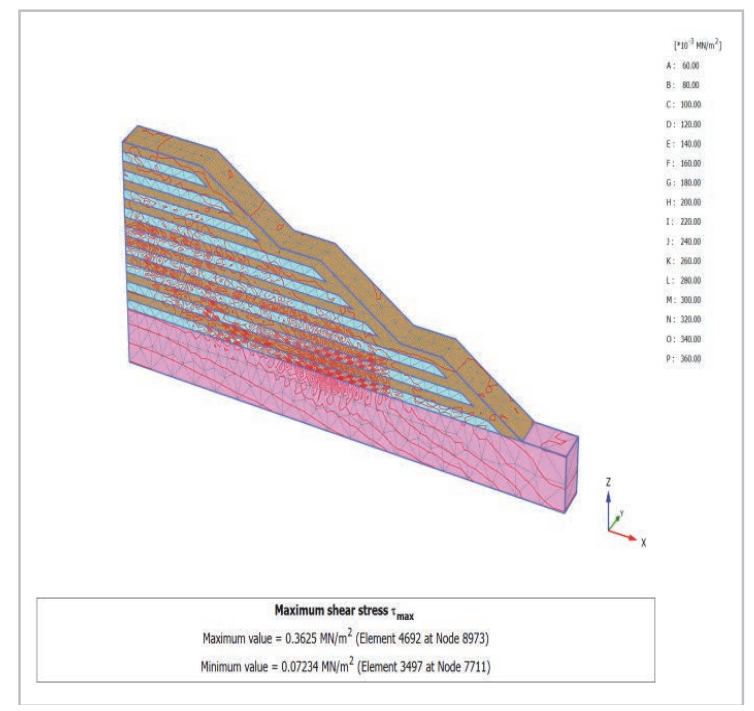

(15b)

Fig. 15. Maximum shear stress shadings \& contour lines

Fig. 15 shows the maximum shear stress $\left(\tau_{\max }\right)$ shadings and maximum shear stress contour lines of the model geometry respectively. Factor of safety at different stages of filling and embankment raising was also evaluated for design with and without drains, the results are shown in the Table 2.

The FOS obtained from numerical modelling indicates that the embankment was stable up to 7 th stage of construction viz. upto a height of $70 \mathrm{~m}$, beyond that the embankment is not stable as the FOS is too low for safe operation.

Table. 2. Fos Of Different Stages Of Construction OF EMBANKMENT BY DOWNSTREAM METHOD

\begin{tabular}{|c|c|c|c|}
\hline \multirow{2}{*}{$\begin{array}{l}\text { Construction } \\
\text { stage }\end{array}$} & \multicolumn{2}{|c|}{$\begin{array}{l}\text { FOS by downstream } \\
\text { method }\end{array}$} & \multirow{2}{*}{$\begin{array}{l}\text { Overall } \\
\text { Embankment slope } \\
\text { angle( } 0 \text { ) }\end{array}$} \\
\hline & $\begin{array}{l}\begin{array}{l}\text { Without } \\
\text { drains }\end{array} \\
\end{array}$ & $\begin{array}{l}\text { With } \\
\text { drains }\end{array}$ & \\
\hline 1st Stage & 1.481 & 2.37 & \multirow{8}{*}{27} \\
\hline 2nd Stage & 1.303 & 1.58 & \\
\hline 3rd Stage & 1.279 & 1.56 & \\
\hline 4th Stage & 1.259 & 1.514 & \\
\hline 5th Stage & 1.246 & 1.453 & \\
\hline 6th Stage & 1.234 & 1.402 & \\
\hline 7th Stage & 1.222 & 1.398 & \\
\hline 8th Stage & 1.102 & 1.116 & \\
\hline
\end{tabular}

VI. CONCLUSION

In this study an extensive laboratory testing has been undertaken to determine physico-mechanical properties of sample. Based on laboratory test numerical simulation of embankment construction has been done for working, slope movement and stability analysis. The following conclusions are drawn from this study:

1. The laboratory and numerical analysis indicates that PA can be safely used for embankment construction along with OB material.

2. PA can be safely used for back filling in the worked out part of Gare IV/I opencast mines. 
3. Downstream method of embankment construction was found to be suitable for containing the high concentration ash fill.

4. However, it is recommended that the height of the embankment should not be raised beyond $70 \mathrm{~m}$ and both horizontal drains should be incorporated in the design.

5. It is also recommended that regular monitoring of the embankment and filling process should be carried out.

\section{ACKNOWLEDGEMENT}

Authors are thankful to the management of Jindal Steel and Power Ltd. for sponsoring the project and for providing all necessary support during field data collection. Thanks are also due to Dr. P. K. Singh, Director, CSIR-CIMFR for his encouragement and kind permission to publish this paper.

\section{REFERENCES}

[1] http://www.cea.nic.in/reports/monthly/installedcapacity/2016/installe d_capacity-03.pdf acm3sed on 03/05/2016.

[2] Report on fly ash generation at coal/lignite based thermal power stations and its utilization in the country for the year 2014-15;CEA.

[3] Craig H., Hans-Joachim F. and Anne W. (2013): "Coal Combustion Products: a Global Perspective", 2013 World Coal Ash (WOCA) Conference, April 22-25, 2013 held at Lexington, KY, USA.

[4] Indian Standard, IS: 2720 (Part V): 1965.

[5] Indian Standard, IS 2720:Part7, 1985.

[6] Duncan C. Wyllie, Christopher W. Mah. (2005): "Rock Slope Engineering", Taylor \& Francis e-Library, 4th edition, pp.177-199.

[7] PLAXIS-3D (2012), Scientific manual, Netherlands, pp. 41-43.

[8] http://run.usc.edu/femdefo/sifakis-courseNotes Theory And Discretization.pdf. 